\title{
ANALYSIS OF THE REGIONAL AIR PASSENGER TRANSPORT SYSTEM IN BRAZIL: SOME ASPECTS OF ITS EVOLUTION AND DIAGNOSIS
}

\author{
S.C. RIBEIRO, C.C.L. FRAGA \& M.P.S. SANTOS \\ Transport Engineering Program, Federal University of Rio de Janeiro, Brazil.
}

\begin{abstract}
Passenger air transport in Brazil, as elsewhere in the world, has been undergoing substantial changes in recent years, not only because of external factors, but also as a consequence of several important changes in the regulatory framework. This paper focuses on the regional aspects of airline passenger traffic in Brazil, based on a review of the literature and interviews with some key government authorities. We first provide an overview of the country's regions and sketch out the historical evolution of regional air transportation in the country. We then discuss the recent changes affecting the sector, considering the regulatory and operational factors at play, particularly in relation to the network of Brazilian cities served by air transport.

Keywords: air transport, commercial aviation, regional air transport, regional development, transport regulation.
\end{abstract}

\section{INTRODUCTION}

Air transportation is a basic input for business, government and tourist activities, as well as for the overall economy. The increasing use of aviation to carry people and goods in recent decades has been one of the most important factors for closer cultural and commercial exchange, contributing directly to improve the welfare of society. Its characteristics of speed and broad geographic coverage make it an important vector for socioeconomic development and an agent to foster territorial unity in many countries [1].

Salgado and Oliveira [2] stress the fundamental role played by the aviation sector, mainly regional air transport, in promoting the sustainable and more balanced development of any country or region. This is particularly true for a country with continental dimensions like Brazil, and also because of the existence of vast areas of tropical forest and relative lack of good roads and railways. For this reason, regional air transport stands out for its strategic importance as an element to spur economic activity in more remote and underdeveloped regions, such as the Amazon and northern part of the country. The stimulus to business in goods and services generates jobs and income, improving the quality of life in these regions.

Graham and Guyer [3] discussed the political and economic aspects resulting from the development of air transport in the regions of the United Kingdom, after the establishment of public policies aimed specifically at the case of regional air transport and airports. More recently, the fundamental importance of regional air transport as a contributor to development of the served regions has been shown by Tapiador et al. [4] for the case of regional airports in Spain. The assessment of the impacts of regional airports on the regional development within the airports economic influence area is considered and analyzed in the work of Malina and Wollersheim [5].

Brazil is the world's fifth largest country in terms of landmass, covering more than 8 million square kilometers. The country is customarily divided into five geographic regions: north, northeast, southeast, midwest and south (Fig. 1). These regions have accentuated differences, not only in geographic terms, but also especially in their social and economic characteristics. This is a relevant aspect when examining the role of regional air transport in Brazil (Table 1).

(C) 2010 WIT Press, www.witpress.com

ISSN: 1743-7601 (paper format), ISSN: 1743-761X (online), http://journals.witpress.com DOI: $10.2495 /$ SDP-V5-N2-141-149 


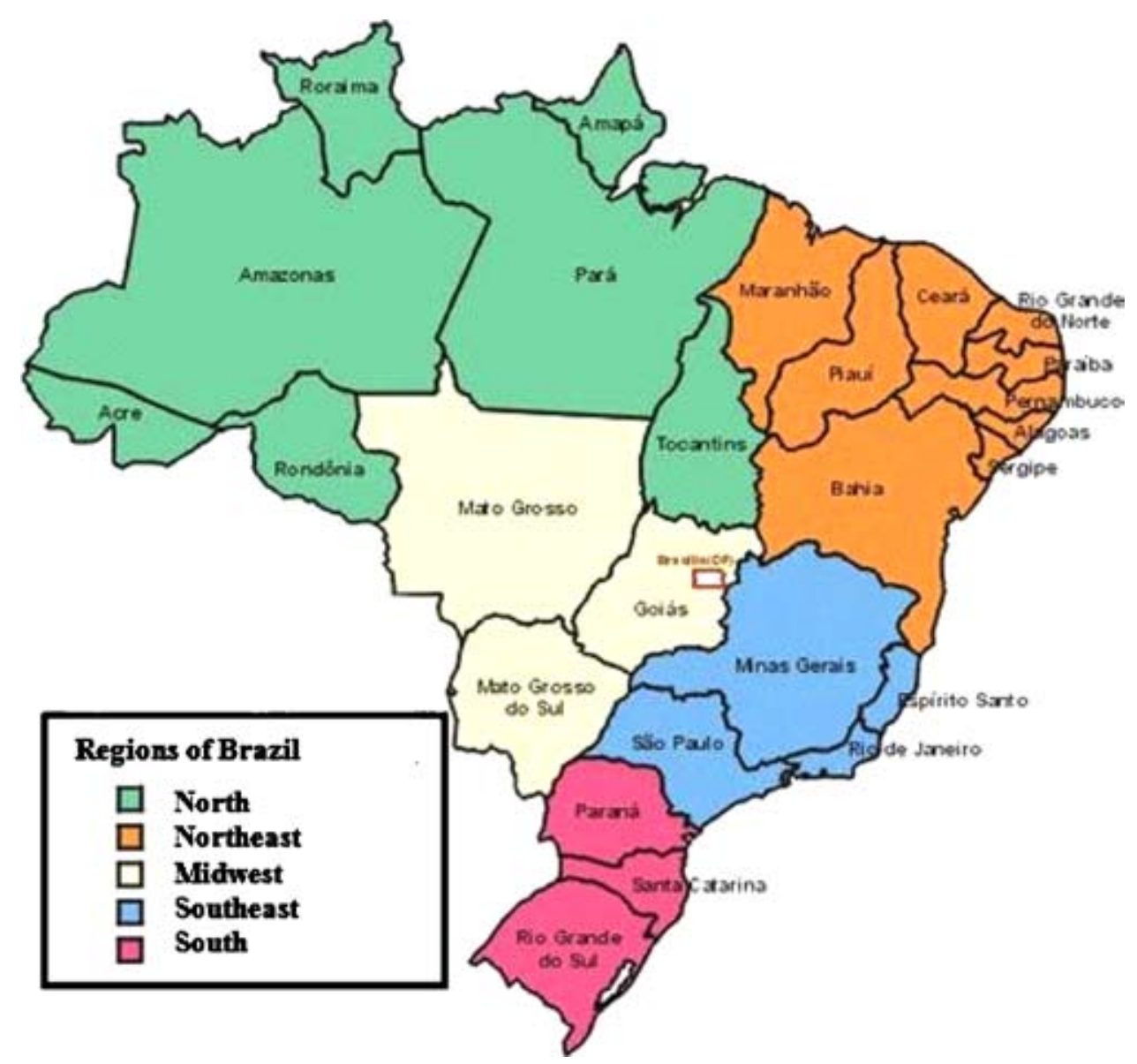

Figure 1: Brazilian regions.

Table 1: Characteristics of Brazilian regions.

\begin{tabular}{|c|c|c|c|c|c|}
\hline & South & Southeast & Midwest & Northeast & North \\
\hline Population (2008) & $26,733,575$ & $77,873,120$ & $13,222,854$ & $51,534,406$ & $14,623,316$ \\
\hline Landmass $\left(\mathrm{km}^{2}\right)$ & 576,000 & 924,511 & $1,606,371$ & $1,554,257$ & $3,853,327$ \\
\hline $\begin{array}{l}\text { Population density } \\
\left(\text { inhab. } / \mathrm{km}^{2}\right)\end{array}$ & 46.41 & 84.23 & 8.23 & 33.16 & 3.80 \\
\hline Share of GDP (\%) & 13 & 58 & 9 & 13 & 5 \\
\hline $\begin{array}{l}\text { Airports in regular } \\
\text { operation }\end{array}$ & 26 & 32 & 22 & 29 & 46 \\
\hline
\end{tabular}

Source: Brazilian Institute of Geography and Statistics [7].

In the face of these geographic and economic characteristics, combined with the historic lack of investments in transport infrastructure, the regional airline sector plays a fundamental role in inducing the country's development. Indeed, air transport is virtually the only way to interconnect some points and to maintain strong regional integration and national political unity [6]. 
Table 1 also shows that the number of cities served, in function of the number of airports with scheduled cargo and passenger traffic in the regions, varies inversely with the population density and level of economic activity.

The Brazilian air transport market has been growing intensively over the last four decades. Table 2 presents the evolution over this time period of the value of seat-km used in comparison to the behavior of the Brazilian economy. The indicator of air transport demand, as represented by seat-km used, has been subjected to substantially higher increase rates when contrasted with the gross domestic product of Brazil. This is particularly noted if the present decade is focused, considering the period between 2000 and 2008 , when the increase rates were $133.8 \%$ and $33.0 \%$, respectively, for the value of seat-km used and gross national product.

The importance of regional air transport for more balanced social and economic development in geographic terms is clear in Brazil, not only because of the Brazilian peculiarities, but also as shown by international experience. However, an examination of the data on the evolution of regional air transport in Brazil shows a gradual reduction in the number of cities served over time. This stands in stark contrast to the important role that regional air transport can play in reducing the sharp social and economic differences among the country's regions. These regions have markedly different population characteristics, with demographic densities varying from 3.8 inhab. $/ \mathrm{km}^{2}$ in the Amazon region (mainly in the North region) to 84.2 in the Southeast, which also concentrates 58\% of the country's gross domestic product (GDP). Because Brazil's population is highly concentrated in urban areas, regions with low population densities can present great physical distances between cities, as is the case in the North (Amazon) and Midwest. These are the very same regions with the smallest shares of the country's GDP, making regional air transport even more important for their social and economic development. It is thus relevant to investigate the role of regional air transport in Brazil based on the standard of service provided to the country's cities and regions.

Although there have been periodic fluctuations, over the past 50 years the number of cities served by scheduled air routes in Brazil has declined from roughly 400 to only 130, according to a study by the magazine Flap Internacional [9]. Figure 2 shows the evolution in recent decades of the number of cities served by scheduled airlines in Brazil (as opposed to air taxi and special charter service).

Within the scheduled domestic air transport sector in Brazil, the regional segment has a very small participation. According to the latest data from the Brazilian Regional Air Transport Association (ABETAR), the market share of this segment does not exceed $2 \%$ of the country's total commercial aviation market. Because of the evidently high potential for regional air transport to serve as an instrument for more geographically balanced economic and social development, there is a need to investigate the factors that have led to this timidity of a segment of such strategic importance, not only for the country's development, but also for its territorial integration and unity. Below we discuss some aspects of the historic evolution of air transport in Brazil, especially regional traffic, followed by an analysis of the current situation.

Table 2: The evolution of Brazilian air transport passenger demand and gross domestic product.

\begin{tabular}{lcccc}
\hline Year & Seat-km used & Variation (\%) & GDP per capita (US\$ millions) & Variation (\%) \\
\hline 1981 & $9,456,380$ & - & $1,516,094.88$ & - \\
1990 & $14,281,498$ & 51.0 & $1,851,108.47$ & 22.1 \\
2000 & 20.493 .072 & 43.5 & $2,367,127.26$ & 27.9 \\
2008 & $47,920,523$ & 133.8 & $3,148,857.55$ & 33.0 \\
\hline
\end{tabular}

Source: Civil Aviation National Agency (ANAC) [8]. 


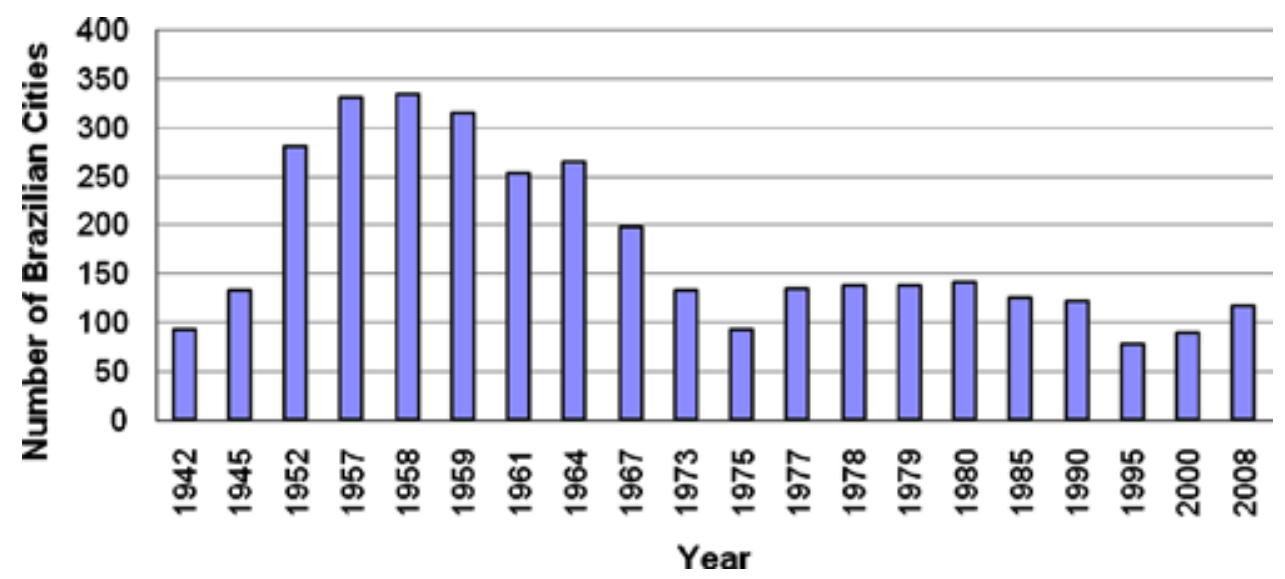

Figure 2: Number of Brazilian cities served by scheduled air transport.

\section{HISTORY OF BRAZILIAN REGIONAL AVIATION}

Brazilian commercial aviation dates back to 1927. One of the most relevant government action taken focused on air transport as an inducer of national integration occurred in 1963. That year the government established a program called the "National Integration Network (Rede de Integração Nacional, or RIN), which provided subsidies to lines using DC-3s and PBY-5 Catalina to serve communities in remote and relatively underdeveloped areas. Later the government created the Integrated Regional Air Transport System (SITAR), endowing it with new resources to stimulate the regional segment.

From an overall perspective, Brazilian commercial aviation has undergone two critical moments in its history regarding its regulation. According to Oliveira [10], these two moments, characterized by two substantial reforms of legislation on the sector, divide the Brazilian aviation into two periods, known as the period of strict regulation (1968-1986) and the period gradual regulatory relaxation (1990-2001). These are discussed in more detail next.

\subsection{Period of strict regulation (1968-1986)}

The period of strict regulation was characterized by direct intervention of the government in Brazilian commercial aviation, with the objective of stimulating its growth by establishing regulatory instruments to support development policy mechanisms.

From the 1940s through the 60s, more than 20 private companies were founded. These flew routes concentrated in the country's more developed regions, particularly along the coast. But this led to oversupply in relation to still incipient demand, at a time when Brazil still had a relatively small internal market, making air transport precarious from an economic perspective.

Malagutti [11] observed that this crisis situation brought an intense lobbying effort by the country's four main carriers: Varig, Vasp, Cruzeiro do Sul and Transbrasil. Their aim was to alert the federal government to the risks of failing to maintain regular and reliable air transportation services. Because of the problems faced by the country's civil aviation industry, the sector's regulator during the period, the Civil Aviation Department (DAC), organized three conferences involving various agents interested in the sector, especially airlines. The aim was to debate and systematize the main questions affecting air transport in Brazil. These events, in their various editions, were known as the National Commercial Aviation Conference (CONAC). 
This effort produced some findings on measures necessary to resolve the problems: reduction of the number of companies by promoting mergers; government regulation of fares and schedules; barriers to the entry of new companies in the market; and division of the market by segment. This was the start of the period known as 'controlled competition', and was implemented by Decree 72,898 in October 1973, by which the four largest carriers were given exclusivity.

One of the consequences of the policies adopted during this period was a decline in demand. The main reason was that the airplanes of these large carriers were not compatible with many Brazilian airports. Thus, from a total of 335 cities served by scheduled routes in 1958, there were only 92 still served in 1975 [12]. This precipitous decline in the number of cities served by air transport prompted the government to establish policies to foster regional aviation. One of the means was to promote the recovery of the scope of the network, by reactivating and maintaining routes that were uneconomic or only marginally profitable, because of medium/low potential passenger traffic, through subsidies. The set of these government policies became concrete with the creation in 1975 of the Integrated Regional Air Transport System (SITAR), under which the country was divided into five areas, each served by one regional monopoly carrier.

There were two main mechanisms created to try to assure the profitability of these regional carriers. The first was the establishment of the 'Tariff Surcharge', which was a surtax of $3 \%$ on the tickets sold by domestic carriers, to be transferred to the SITAR system as a form of cross-subsidy to the regional carriers. The second was the creation of special credit lines for the purchase of aircraft made domestically. The main model was the medium-range Bandeirante, made by Embraer (at the time under government control). This policy also sought to stimulate development of the Brazilian aeronautical industry [9].

\subsection{Period of relaxation of Brazilian commercial aviation regulation (1990-2001)}

As the name suggests, the period of relaxation of commercial aviation regulation saw the undoing of much of the former regulatory framework. The federal government made this official in the Federal Deregulation Program, ushering in the 'Policy to Flexibilize Commercial Aviation', instituted through a series of edicts issued by the Civil Aviation Department (DAC), part of the Defense Ministry (more specifically the Air Force). The overall aims of this policy were to stimulate the opening of the market and the introduction of competition in it, with the extinction of the monopolies and segmentation, along with reduced regulation of fares (Oliveira [10]). This program was carried out in three steps, starting, respectively, in 1992, 1998 and 2001, as described below.

\subsubsection{First liberalization step (1992-1997)}

The first liberalization step was initiated after a meeting of the National Civil Aviation Council (CONAC), established to advise the executive branch on civil aviation questions. At this meeting, some decisions were taken to extinguish the five regional airline monopolies that had been established under the Regional Air Transport System (SITAR) in the 1970s. This policy, which also ended monopolies on certain routes granted to nationwide carriers, provided a new dynamic to the market, with the ability of new competitors to enter the fray.

During this first step of liberalization, fares were not totally deregulated; their control was only relaxed. 'Tariff bands' were created, allowing airlines to offer tickets at prices ranging from 50\% under to $32 \%$ over the benchmark fare. This was a big advance in terms of competition, in contrast to the rigid system of price controls in the previous period, when fares were strictly regulated. 


\subsubsection{Second liberalization step (1998-2001)}

The second step of liberalizing the air transport market was marked by the adoption to two strategies by the Brazilian government, both aimed at eliminating fare controls. The first strategy consisted of removing the 'tariff band' system, stimulating greater competition. The second was the extinction of restrictions on the operation of lines called special, represented by routes linking the central airports of the main Brazilian cities. These two measures spurred an intense competitive movement that culminated in a true 'fare war', as observed by Salgado and Oliveira [2].

However, the situation of the airline industry changed drastically starting in early 1999 with the exchange rate volatility after the fixed exchange rate regime was abandoned in favor of a floating regime. The resulting steep devaluation of the Brazilian currency (Real) against the dollar caused a spike in operating costs of Brazilian airlines, prompting them first to suspend promotional fares, and then to raise prices across the board. This required intervention by the federal government to authorize them to raise fares above the upper bound of the fare band.

\subsubsection{Third liberalization step (2001-2003)}

The third step of the liberalization process began on August 16, 2001, when a new agreement between the Civil Aviation Department, the regulatory agency of the Defense Ministry, and the Finance Ministry established 'total freedom' to set prices. There were various effects of this measure, such as the entrance of new companies, various requests to operate new routes, frequencies and flights. One of the most representative occurrences of this period was the emergence of the airline Gol Transportes Aéreos, considered the first Brazilian 'low cost and low fare' carrier [13].

There have been other events regarding regulation of the air transport market in Brazil since the end of the third step. However, the measures involved have not represented significant changes for the analysis of regional air transport in Brazil.

\section{EVOLUTION OF REGIONAL AIR TRANSPORT IN BRAZIL}

The need for a more homogeneous definition of the regional air transport segment among the various agents involved is a difficulty that needs to be considered in the analysis of regional air transport in Brazil.

The concept of regional air transport in Brazil arose in 1975 with the establishment of specific government policies for this segment, with the aim of enhancing the country's regional integration. Decree 76,590, issued in November 1975, created the Regional Air Transport System (SITAR), formally tied to the five regions into which the country is traditionally divided, as discussed before. With the end of this system in 1999, the concept of regional air transport became diluted into a varied set of carriers, routes and regulatory aspects.

Currently the concept is roughly associated with any scheduled route linking state capitals (which are nearly always the largest cities in the respective states) with cities in their hinterlands. However, this oversimplification does not consider all the criteria involved (distance covered, geographic region, type of aircraft, number of inhabitants in the cities generating demand, among others) in determining what regional air transport is nowadays. For Salgado and Oliveira [2], the criteria for defining regional markets in practice are demarcation based on airline company, type of aircraft (smaller airplanes characterizing regional carriers), population (cities with fewer than one million inhabitants), traffic density (up to 15,000 passengers/year) and route length (up to 1,000 kilometers).

Below we analyze the evolution of air transportation in Brazil in function of the number of cities served over time and how these cities are distributed in terms of their populations. To make the source of data homogenous, we used the monthly figures published by the magazine Panrotas [14], since 1953. We systematized the data obtained into a historic series from 1953 to 2008 for the total 
number of cities served, and for the years 1970, 1980, 1990, 2000 and 2008 with respect to the cities served classified by population level.

The evolution over time of the number of cities served by scheduled air transport is shown in Fig. 3. It can be seen that the number of cities served peaked in 1958 and then declined to fewer than 100 cities served in 1975 for the first time since 1942. During the period considered, many factors combined to produce this pattern, such as the growth of land transport (particularly new highways), technological evolution of the transport sector, especially regarding aircraft, and the pattern of regional development of the country, with increasing populations concentrated in large urban areas. As mentioned, in 1975 the federal government established a program to stimulate regional air transport, aiming to boost development of interior regions of the country and increase territorial integration. The result was that starting in 1975 the number of cities served started to rise again. This lasted until 1990, when, possibly because of deregulation, the number of cities served began to fall sharply, bottoming out in 1995. Since then, the number of cities served has grown again until 2008, but still far short of the peaks reached in the 1950s.

To provide more detail on the variation in the number of cities served by scheduled air routes over time, we classified the set of cities by population ranges. We adopted the following population intervals: fewer than 100,000 inhabitants; between 100,000 and 300,000 inhabitants; between 300,001 and 500,000 inhabitants; between 500,001 and 1,000,000 inhabitants; and more than 1,000,000 inhabitants. It is reasonable to assume that the larger the number of small and medium cities served by air transport, the greater the contribution of this system to more balanced economic and social development of the country's regions.

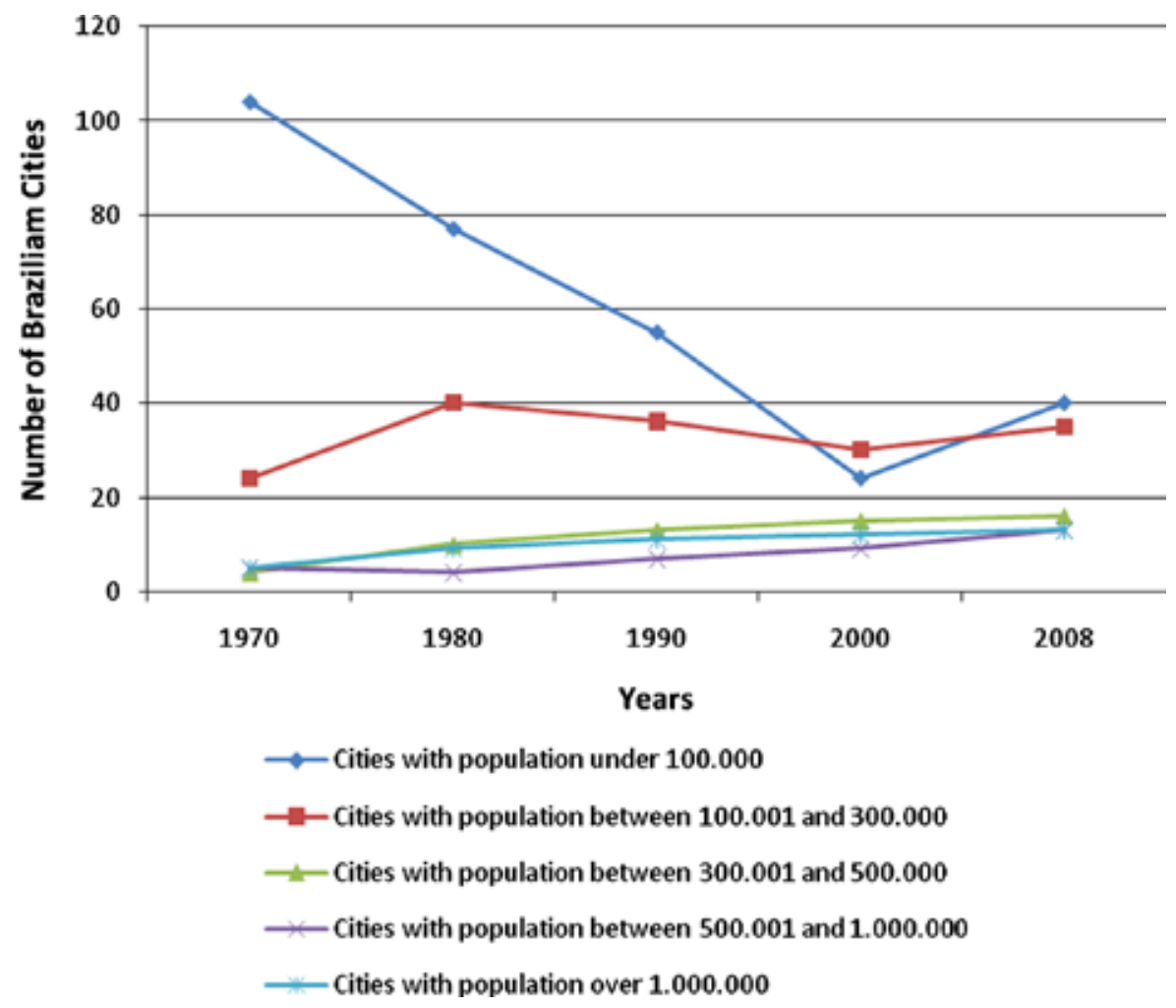

Figure 3: Cities served by air transport by population range. 
The variation in the number of cities served by scheduled air transport, broken down by the different population intervals, is presented in Fig. 3.

The main point that stands out in Fig. 3 is the reversal of the trend in the variation of the number of cities with fewer than 100,000 people in the past 40 years. The number of 'small' cities (population under 100,000) served by scheduled air transport fell sharply and steadily from 1970 to 2000, then it began to rise again until 2008. After the interval of greatest changes in the sector's regulation, with no new public policy to stimulate regional air transport as occurred previously, the number of small cities served almost doubled between 2000 and 2008. The same pattern since 2000 can be observed for cities with between 100,000 and 300,000 inhabitants, albeit less accentuated. Together these two facts suggest a broader reversal in the composition of the network of cities served by scheduled air transport in Brazil.

For cities with larger populations the variations over this period remained relatively stable. This is partly a consequence of the country's substantial population growth over the period, and the increasing concentration in urban areas, as mentioned before. Particular attention is warranted to the greater growth of the number of cities with between 300,001 and 500,000 people. The set of evidence analyzed appears to indicate a growing trend in the pattern of scheduled air transport service to smaller cities. If this trend becomes better established, it can indicate that the contribution of regional air transport is becoming increasingly important for the country's more balanced and equitable regional development within the existing economic and social context.

\section{CONCLUSIONS}

The picture that emerges from the evidence presented here is one of great changes in the pattern of air transport in Brazil regarding the number of cities served. After a period of general decline since the end of the 1950s, with some variations because of measures adopted by the federal government, in recent years there has been a clear reversal of this downward trend.

The experience with public policies in Brazil specifically aimed at stimulating regional air transportation, starting with the implementation of the SITAR (Regional Air Transport System) in 1975, was not continued, nor has there been any analysis of the possible contributions of these policies to Brazilian regional development. There is a particular need to examine the role of regional air transport in regions with large territorial extent and population dispersion, as in the Midwest and North, especially the Amazon.

The treatment of the problem just from the number of cities served, even with their classification by population range, produces a result that should be analyzed with care. Besides factors linked to the sector's regulation, there are other influences with distinct magnitude, such as those involving technological and industrial aspects of the air transport sector, the participation and integration of other transportation modes in the national context and other government national policies for development and integration.

\section{REFERENCES}

[1] Moura, G.B., Transporte aéreo e responsabilidade civil/Air Transport and Civil Responsability, Aduaneira: São Paulo, Brazil, 2002.

[2] Salgado, L.H. \& Oliveira, A.V.M., Constituição do marco regulatório para o mercado Brasileiro de aviação nacional/Regulatory Aspects for the Brazilian Regional Air Transport Market, Nectar/ITA São José dos Campos: São Paulo, Brazil, 2008. http://www.nectar.ita.br.

[3] Graham, B. \& Guyer, C., The role of regional airports and air services in the United Kingdom. Journal of Transport Geography, 8, pp. 249-262, 2000. doi:10.1016/S0966-6923(00)00021-1

[4] Tapiador, F.J., Mateos, A. \& Mart1-Henneberg, J., The geographical efficiency of Spain's regional airports: a quantitative analysis. Journal of Air Transport Management, 14, pp. 205-212, 2008. doi:10.1016/j.jairtraman.2008.04.007 
[5] Malina, R. \& Wollersheim, C., The regional impact of airports: how can we measure it? Aerlines Magazine, 2008.

[6] Silva, W.P., Sistema integrado de informações geográficas e técnicas de alocação para análise da demanda por transporte aéreo de passageiros. DSc. Thesis, Transport Engineering Program, Federal University of Rio de Janeiro, Rio de Janeiro, Brazil, 2000. http://www.pet.coppe.ufrj.br.

[7] IBGE, Instituto Brasileiro de Geografia e Estatística/Brazilian Institute for Geography and Statistics, Brasília, Brazil. http://www.ibge.gov.br.

[8] ANAC, Agência Nacional da Aviação Civil/Civil Aviation National Agency. http://www.anac. gov.br.

[9] Flap Internacional, 427. Grupo Editorial Spagat: São Paulo, Brazil, 2008.

[10] Oliveira, A.V.M., Transporte aéreo e políticas públicas/Air Transport and Public Policy, Pezco: São Paulo, Brazil, 2009.

[11] Malagutti, A.O., Evolução da aviação civil no Brasil/Civil Aviation Evolution in Brazil. Câmara dos Deputados. Aérea XVII Segurança e Defesa Nacional: Brasília, Brazil, 2001.

[12] Gomes, S., Lacerda, S., Bastos, V. \& Castro, M., Aviação Regional Brasileira/Brazilian Regional Aviation). Informe Infra-Estrutura - Banco Nacional de Desenvolvimento Econômico e Social/National Bank for Social and Economic Development - BNDES 50. Rio de Janeiro, Brazil, 2002. http://www.bndes.gov.br.

[13] Palhares, G.L., Transporte aéreo e turismo: gerando desenvolvimento socioeconômico/Air Transport and Tourism: Promoting Social and Economic Development, Aleph: São Paulo, 2001.

[14] Panrotas, Editora Panrotas, São Paulo, Brazil, 1953-2008. 